Section Editor

Mitchell S.V. Elkind,

MD, MS

Mystery Case:

\title{
A 63-year-old man with progressive proximal pain and weakness
}

Patricia D. Scripko, MD, MA

Anthony A. Amato, MD

Alberto Puig, MD, PhD, FACP
PART 1 A 63-year-old man with a history of type 2 diabetes presented with hip and shoulder pain in June 2010. He was on atorvastatin $80 \mathrm{mg}$ daily and his creatine kinase (CK) was mildly elevated, so he was switched to simvastatin $20 \mathrm{mg}$ daily. Three months later, he was referred to a rheumatologist. His CK was $142 \mathrm{U} / \mathrm{L}$ and his erythrocyte sedimentation rate (ESR) and C-reactive protein (CRP) were mildly elevated $(28 \mathrm{~mm} /$ hour and $14 \mathrm{mg} / \mathrm{L}$, respectively). $\mathrm{He}$ was diagnosed with polymyalgia rheumatica. $\mathrm{He}$ was started on a methylprednisolone taper starting at $16 \mathrm{mg}$ going to $8 \mathrm{mg}$ daily with mild, although transient, improvement. He remained on $8 \mathrm{mg}$ daily methylprednisolone for several months. Eight months later, he began to notice progressive proximal leg weakness and difficulty climbing stairs. His serum CK was 1,600 U/L. He stopped the simvastatin and was started on gemfibrozil. An EMG was normal. His CK rose to the 3,000s U/L 3 months later. Nine months later, 8-day methylprednisolone tapers starting at $16 \mathrm{mg}$ daily were symptomatically ineffective, as was prednisone $60 \mathrm{mg}$ daily tapered over 2 weeks.

He declined steadily for about 6 weeks and then was admitted for frequent falls along with an unintentional 30-pound weight loss. In addition, he reported occasional choking on both solid food and liquids for the past several months but no slurred speech, diplopia, drooling, or shortness of breath. $\mathrm{He}$ had no muscle pain and his CK was over $7,000 \mathrm{U} / \mathrm{L}$ the day prior to admission. His examination was notable for weakness. Manual muscle testing revealed the following Medical Research Council (MRC) scores: neck flexion 4, shoulder abduction and flexion 4, elbow extension and flexion 4, hip flexion 3, hip extension 4, knee flexion $5-$, otherwise he was grade 5 . He had reduced sensation up to his shins with absent ankle jerks, and $1+$ reflexes otherwise throughout. Plantar responses were flexor. His gait was slightly widebased and he could walk on his toes and heels without difficulty. He did not have a Romberg sign.

\section{Questions for consideration:}

1. What is the differential diagnosis for the progressive, proximal, symmetric weakness?

2. What is the significance of an elevated CK? Does it help differentiate the localization between muscle and nerve?

3. What laboratory, imaging, physiologic, or pathologic studies will help clarify the diagnosis?

PART 2 The differential for symmetric, proximal weakness includes a myopathy, neuromuscular junction (NMJ) disorder, and possibly a neurogenic process. Most NMJ disorders (e.g., myasthenia gravis and Lambert-Eaton syndrome) have ocular or bulbar symptoms along with extremity weakness along with fatigability on examination. Most neurogenic disorders manifest with distal-greater-than-proximal weakness but not with only proximal weakness (the exception being some hereditary spinal muscular atrophies). Prominent involvement of proximal muscles is more common in myopathies, though there are myopathies that preferentially affect the distal muscles. The markedly elevated serum CK of 3,000 U/L a year prior to presentation and admission CK of $>7,000$ U/L strongly support a myopathic process. The differential diagnosis of proximal weakness is quite broad (table).

The following pertinent serologic studies were unremarkable: normal serum protein electrophoresis, ESR, and CRP; mildly positive antinuclear antibodies (1:40 speckled pattern); negative Jo- 1 antibodies; and normal thyroid-stimulating hormone and vitamin $\mathrm{B}_{12}$.

CT chest/abdomen/pelvis showed no evidence of malignancy, and his C-spine MRI showed severe cervical stenosis from C3 to C6 with myelomalacia. An EMG was repeated and was reported as showing both neurogenic and myopathic processes. A right biceps biopsy was performed at an outside facility. Our review of the muscle biopsy slides revealed fiber type grouping, targetoid fibers, and nuclear bags. Also noted were scattered necrotic and regenerating fibers and myophagocytosis of necrotic fibers but little other

From the Department of Neurology (P.D.S.) and Clinician Educator Service (A.P.), Massachusetts General Hospital; the Department of Neurology (A.A.A.), Brigham and Women's Hospital; and Harvard Medical School (A.P.), Boston, MA.

Go to Neurology.org for full disclosures. Funding information and disclosures deemed relevant by the authors, if any, are provided at the end of the article. 


\section{Table Differential diagnosis of adult-onset myopathies with chronic progressive proximal weakness}

Hereditary

Muscular dystrophy (e.g., limb-girdle, Becker)

Myotonic dystrophy type 2

Muscle channelopathies (periodic paralysis, nondystrophic myotonias)

Certain "congenital" myopathies (central core, multiminicore, centronuclear, nemaline rod)

Metabolic myopathies (glycogen and lipid disorders)

Mitochondrial myopathies

Acquired

Inflammatory myopathies

Dermatomyositis

Polymyositis

Inclusion body myositis

Autoimmune necrotizing myopathies

Granulomatous/sarcoid

Infectious myositis

Toxic myopathies

Endocrinopathies (hyperthyroid and hypothyroid, secondary hyperparathyroid, vitamin D deficiency)

Amyloidosis

Late-onset rod myopathy does not respond to prednisone alone, ${ }^{1}$ we almost always start treatment with both high-dose prednisone and a second-line immunosuppressive agent at the same time (usually methotrexate as it tends to work faster). In very severe cases such as this we usually also simultaneously start IV immunoglobulin. Therefore, he was started on prednisone $60 \mathrm{mg}$ daily, methotrexate $15 \mathrm{mg}$ weekly, and IV immunoglobulin G $2 \mathrm{mg} / \mathrm{kg}$ monthly immediately following diagnosis. After 3 months, his muscle strength and function improved. Manual muscle testing now revealed the following MRC scores: neck flexion 5, shoulder abduction and flexion 4, elbow extension and flexion 5 , hip flexion $4+$, hip extension $4+$, knee flexion 5 . His CK also normalized to $124 \mathrm{U} / \mathrm{L}$.

A statin-triggered immune-mediated necrotizing myopathy is the likely etiology and cause of this patient's presentation.

Immune-mediated necrotizing myopathy may be idiopathic (e.g., may be associated with autoantibodies directed against signal recognition particle ${ }^{1}$ ), paraneoplastic, ${ }^{2}$ related to a connective tissue disease, ${ }^{3}$ or statin-induced. ${ }^{4-6}$ Therefore, cancer screening and autoimmune workup should always be performed. Our patient reported a 30-pound weight loss, concerning for a systemic process, but evaluation has been unrevealing and this often results from severe loss of muscle mass in subacute and chronic myopathic processes.

While statin-induced toxic myopathy is welldescribed, only rarely do patients present with persistent or worsening weakness after the statin has been discontinued. In these cases, an immune-mediated necrotizing myopathy should be suspected and immunosuppressive therapy is likely necessary for stabilization and improvement. Recent studies have described this entity in detail. ${ }^{4-6}$ Needham et al. ${ }^{5}$ reported 8 cases of necrotizing myopathy in the setting of statin use that did not improve after statin cessation. Five of these patients had absence of inflammation on biopsy, and only one had significant inflammation. Grable-Esposito et al. ${ }^{4}$ reported 25 patients diagnosed with statin-associated immune-mediated necrotizing myopathy. The average duration of statin exposure was 3 years. Nine patients developed weakness after the statin was stopped and 16 developed weakness while taking the statin. CK levels ranged from 500 s to 1,200 s U/L prior to initiation of immunotherapy. Most patients required multiple immunosuppressive medications, and, when discontinued, clinical flares often occurred. Biopsies showed necrotizing and regenerating fibers without an inflammatory infiltrate and some revealed MAC immunostaining of the sarcolemma of non-necrotic muscle fibers. It is possible that MAC deposition results in complement-mediated damage to the muscle. However, the MAC deposition may just be 


\section{Figure Left biceps biopsy}

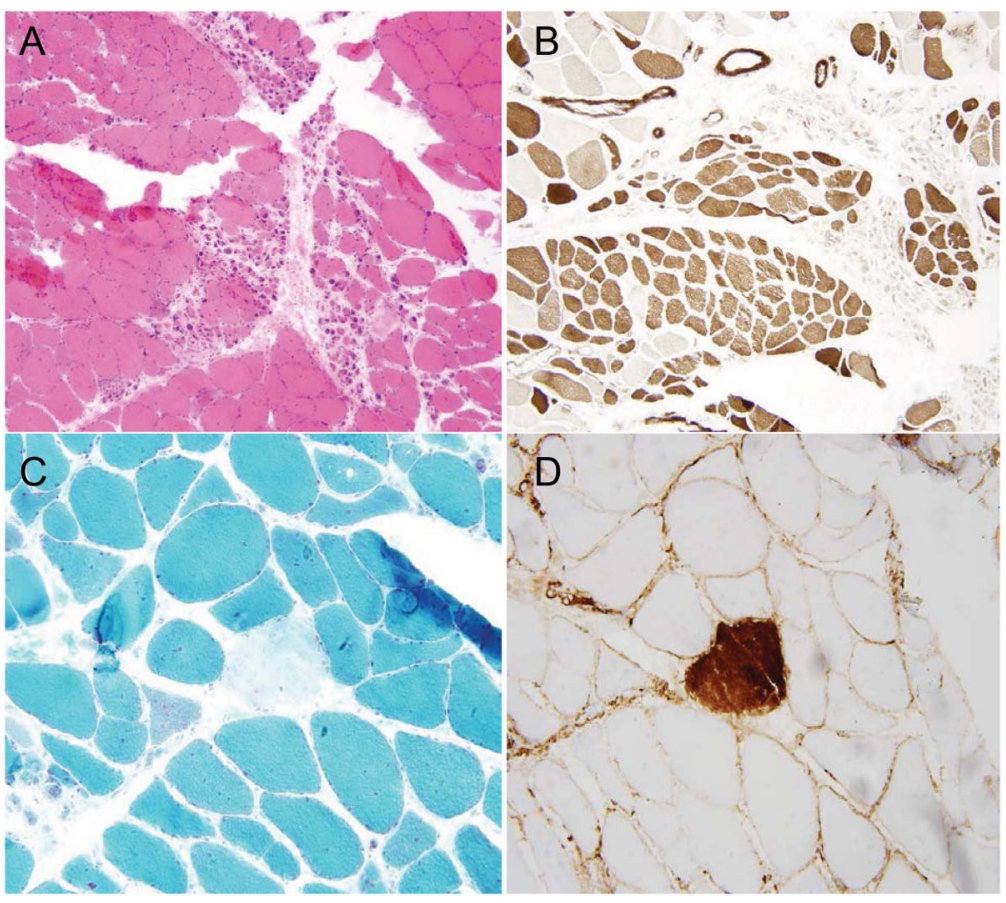

(A) Group atrophy, hematoxylin \& eosin. (B) F fiber type grouping suggestive of chronic denervation with reinnervation, ATPase 4.6. (C) A necrotic muscle fiber, modified Gomori trichrome. (D) Membrane attack complex (MAC) deposition diffusely on the 2 necrotic muscle fibers as well as the sarcolemma of non-necrotic muscle fibers, MAC immunoperoxidase.

a secondary phenomenon, as deposition of MAC can occur secondarily on abnormal muscle membranes. For example, MAC deposition occurs secondarily on muscle membranes in some muscular dystrophies (e.g., dysferlinopathies).

The etiology of this immune-mediated necrotizing myopathy is not fully understood. An autoantibody directed against 3-hydroxy-3-methylglutaryl coenzyme A reductase (HMG CoA-R, a cholesterol reductase) has been identified in a majority of patients with a late-onset necrotizing myopathy who were exposed to statins. ${ }^{6}$ These antibodies were not usually detected in patients with the more typical statin myopathies that reverse with discontinuation of statins or in asymptomatic patients on statins. ${ }^{7}$ Whether or not these antibodies are causal or represent etiologic epiphenomena is not known.

A diagnosis of immune-mediated necrotizing myopathy should be considered in patients with suspected statin-induced myopathy in whom symptoms persist or worsen despite discontinuation of drug exposure. Additionally, aggressive treatment with immunotherapy should be promptly initiated once diagnosis is established, as delay in therapy may be detrimental and result in severe destruction of muscle mass that often does not fully regenerate even after successful symptomatic treatment is started. While the pathogenesis of the disease is unknown, it is likely to be autoimmune in nature. Ongoing research may help clarify the relationship between the HMGCoA-R antibodies and the pathogenesis of the disease. Ultimately, detection of these antibodies may facilitate the diagnosis and prove instrumental in early treatment of this disease.

\section{AUTHOR CONTRIBUTIONS}

Dr. Scripko was responsible for the concept and drafting of the manuscript. Dr. Amato provided critical revisions and supervision. Dr. Puig provided critical revisions.

\section{STUDY FUNDING}

No targeted funding reported.

\section{DISCLOSURE}

P. Scripko reports no disclosures. A. Amato reports being on the Medical Advisory Board for Amgen, MedImmune, Biogen, and Baxter. A. Puig reports no disclosures. Go to Neurology.org for full disclosures.

\section{REFERENCES}

1. Benveniste $\mathrm{O}$, Drouot L, Jouen F, et al. Correlation of antisignal recognition particle autoantibody levels with creatine kinase activity in patients with necrotizing myopathy. Arthritis Rheum 2011;63:1961-1971.

2. Emslie-Smith AM, Engel AG. Necrotizing myopathy with pipestem capillaries, microvascular deposition of the complement membrane attack complex (MAC), and minimal cellular infiltration. Neurology 1991;41:936-939.

3. Levin MI, Mozaffar T, Al-Lozi MT, Pestronk A. Paraneoplastic necrotizing myopathy: clinical and pathological features. Neurology 1998;50:764-767.

4. Grable-Esposito P, Katzberg HD, Greenberg SA, et al. Immune-mediated necrotizing myopathy associated with statins. Muscle Nerve 2010;41:185-190.

5. Needham M, Fabian V, Knezevic W, et al. Progressive myopathy with upregulation of MHC-I associated with statin therapy. Neuromuscul Disord 2007;17:194-200.

6. Mammen AL, Chung T, Christopher-Stine L, et al, Autoantibodies against 3-hydroxy-3-methylglutaryl-coenzyme A reductase in patients with statin-associated autoimmune myopathy. Arthritis Rheum 2011;63:713-721.

7. Mammen AL, Pak K, Williams EK, et al. Rarity of anti-3hydroxy-3-methylglutaryl-coenzyme A reductase antibodies in statin users, including those with self-limited musculoskeletal side effects. Arthritis Care Res 2012;64:269-272.

MYSTERY CASE RESPONSES The Mystery Case series was initiated by the Neurology ${ }^{\circledR}$ Resident \& Fellow Section to develop the clinical reasoning skills of trainees. Residency programs, medical student preceptors, and individuals were invited to use this Mystery Case as an educational tool. Responses were solicited through a group e-mail sent to the American Academy of Neurology Consortium of Neurology Residents and Fellows and through social media.

All the responses that we received came from individuals rather than groups. Every respondent identified the necrotic muscle fibers on the modified Gomori trichrome stain, while $50 \%$ of respondents correctly identified the findings of group atrophy on 
hematoxylin \& eosin and MAC deposition on MAC immunoperoxidase. All the respondents recognized that an immune-mediated necrotizing myopathy is the most likely etiology for the patient's presentation, but the most complete response came from Ichizo Nishino, who noted that the disease process was likely triggered by the patient's use of a statin.

As the authors emphasized, immune-mediated necrotizing myopathy is a rare complication of statin use, but it must be considered in patients who have been treated with a statin and have persistent or progressive symptoms after withdrawal of the offending medication. Once other etiologies such as paraneoplastic disorders have been ruled out, treatment with aggressive immunotherapy will optimize patients' long-term recovery.

Andrew Schepmyer, MD

Department of Neurology, University of British Columbia, Vancouver, Canada 


\section{Neurology}

\section{Mystery Case: A 63-year-old man with progressive proximal pain and weakness}

Patricia D. Scripko, Anthony A. Amato and Alberto Puig

Neurology 2014;82;e26-e29

DOI 10.1212/WNL.0000000000000052

This information is current as of January 27, 2014

\section{Updated Information \& Services}

References

Subspecialty Collections

\section{Permissions \& Licensing}

Reprints including high resolution figures, can be found at: http://n.neurology.org/content/82/4/e26.full

This article cites 7 articles, 2 of which you can access for free at: http://n.neurology.org/content/82/4/e26.full\#ref-list-1

This article, along with others on similar topics, appears in the following collection(s):

\section{All Neuromuscular Disease}

http://n.neurology.org/cgi/collection/all_neuromuscular_disease Autoimmune diseases

http://n.neurology.org/cgi/collection/autoimmune_diseases

EMG

http://n.neurology.org/cgi/collection/emg

Muscle disease

http://n.neurology.org/cgi/collection/muscle_disease

Other toxicology

http://n.neurology.org/cgi/collection/other_toxicology

Information about reproducing this article in parts (figures,tables) or in its entirety can be found online at:

http://www.neurology.org/about/about_the_journal\#permissions

Information about ordering reprints can be found online:

http://n.neurology.org/subscribers/advertise

Neurology ${ }^{\circledR}$ is the official journal of the American Academy of Neurology. Published continuously since 1951, it is now a weekly with 48 issues per year. Copyright @ 2014 American Academy of Neurology. All rights reserved. Print ISSN: 0028-3878. Online ISSN: 1526-632X.

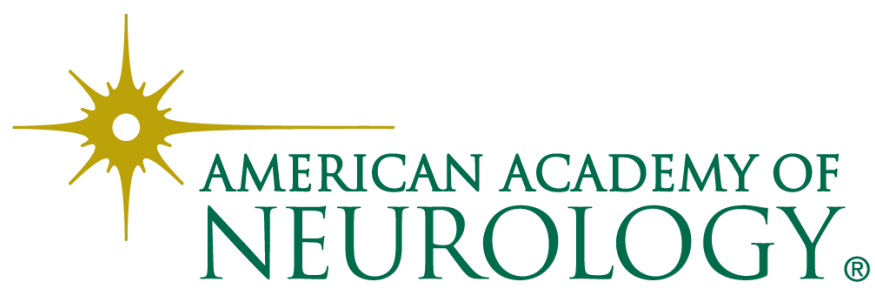

